\title{
Curative use of forequarter amputation for recurrent breast cancer over an axillary area: a case report and literature review
}

\author{
Chun-Hao Tsai ${ }^{1,2}$, Huey-En Tzeng 2,3 ${ }^{2,3}$ Wei-Kae Juang ${ }^{4}$, Pei-Guo Chu ${ }^{5}$, Patricia Fann ${ }^{6}$, Yi-Chin Fong ${ }^{1,7}$, \\ Horng-Chaung $\mathrm{Hsu}^{1,2}$ and Yun Yen ${ }^{8,9^{*}}$
}

\begin{abstract}
Axillary recurrence of breast cancer that involves the brachial neurovascular bundle is uncommon. However, for many patients with such recurrence, forequarter amputation can play a palliative role in relieving excruciating pain and paralysis of the upper limb. Further, for those patients who do not have distant metastasis or other local-regional recurrence, forequarter amputation provides a chance for a cure. Only a few case reports of curative amputations for recurrent breast cancer are present in the literature. Here, we report a case of forequarter amputation for curative treatment of axillary recurrent breast cancer, together with a literature review. To date, we have followed the patient for three years after amputation, during which there has been no evidence of recurrence or metastasis. Although radical resection is feasible, it can be accompanied by surgical wound complications and psychosocial stress. Therefore, an organized multidisciplinary approach is needed to ensure the success of radical resection.
\end{abstract}

Keywords: Breast cancer, Forequarter amputation, Recurrence

\section{Background}

As medical treatment of breast cancer has improved, radical amputation as a means of treatment is less often performed. Forequarter or interscapulothoracic amputation involves removing the entire upper extremity, including the ipsilateral scapula and clavicle. Use of forequarter amputation to treat recurrent breast cancer was first reported in 1900 by Buchanan [1], and four additional cases were reported by Pack in 1942 [2]. Since then, few instances of forequarter amputation for the surgical management of recurrent breast cancer have been reported. Indeed, to date, including the cases mentioned above, only 23 cases of forequarter amputation to treat recurrent breast cancer have been described in the literature, and only five of these amputations were performed primarily for curative purposes [3-6]. Here, we report the case of a patient with

\footnotetext{
* Correspondence: YYen@coh.org

${ }^{8}$ Department of Molecular Pharmacology, City of Hope National Medical Center and Beckman Research Center, 1500 East Duarte Road, Duarte, CA 91010, USA

${ }^{9}$ The PhD Program for Cancer Biology and Drug Discovery, Taipei Medical University, 250 Wuxing Street, Taipei City 110, Taiwan

Full list of author information is available at the end of the article
}

metastatic breast adenocarcinoma who underwent forequarter amputation.

\section{Case presentation}

In 2002, a 52-year-old asian woman underwent a lumpectomy for a stage II infiltrating duct carcinoma over her right breast, followed by four cycles of adjuvant chemotherapy combining doxorubicin, cyclophosphamide and paclitaxel. Chemotherapy was followed by locoregional radiation. Eight years after the completion of chemotherapy, she found a slowly growing mass on her right neck. Positron emission tomography (PET) scan revealed large infraclavicular mass and a supraclavicular adenopathy of the right neck and right nasal cavity. Analysis of biopsy samples from both masses was consistent with metastatic carcinoma and suggestive of the metastasis having arisen from primary breast cancer. She underwent removal of the right supraclavicular and infraclavicular masses at that time, followed by adjuvant chemotherapy. However, one year after the surgery, she found a mass in the upper outer quadrant of her right anterior chest wall. Ulceration and bleeding of the mass caused her to have a painful disability of her right upper limb. A computed tomography (CT) 
scan (Figure 1a) revealed a mass in the upper outer quadrant of her right anterior chest wall. The mass had invaded the ribs and pleura. Magnetic resonance imaging (MRI, Figure $1 \mathrm{~b}$ ) revealed that the mass involved the axillary artery and occluded the right lateral subclavian vein and axillary vein.

After a multimodality assessment followed by discussion of the available options and risks, benefits and subsequent rehabilitation associated with forequarter amputation with the patient and her family, she consented to the amputation. Surgery revealed a fungating tumor in the anterior superior chest wall that involved the right first, second and third ribs. This tumor had adhered to the right lung as well as the brachiocephalic-subclavian vein and artery.

During surgery, the patient was placed in a semi-lateral position on her left side with her right side elevated at a $45^{\circ}$ angle. An incision was made over her sternocleidomastoid muscle, about $3 \mathrm{~cm}$ above where the muscle attaches to the clavicle. The incision was directed posteriorly around the posterior triangle of the neck, around the scapula, under the axilla(including an extension along the latissimus dorsi muscle to allow for proper flaps) and then anteriorly around the mass and across the chest wall. Subcutaneous dissection was done along the anterior border of the manubrium and the right first, second and third ribs. For the scapulectomy, an incision was made in the patient's back, and the teres major and latissimus dorsi were dissected to obtain negative margins. The latissimus dorsi muscle was completely transected from the chest wall and scapula and a flap was created under the teres major. The intercostal continuous dissection was carried up to the neck. The platysma muscle was divided, and the sternocleidomastoid muscle identified and divided to identify the jugular vein, carotid artery and vagus nerve. Once the neck musculature was divided and the carotid sheath contents isolated, the posterior scalene muscle was clearly identified. Then the posterior scalene muscles were divided sequentially while the brachial plexus branches were identified. At that time, the phrenic nerve was traced and dissected from the tumor, and the brachiocephalic vein and internal jugular vein that had adhered to the tumor were ligated. The remaining attachments of the structures to the tumor and arm were dissected, including the subclavian artery and first ribs. Then the chest wall was covered and reconstructed with the free forearm flap. Histological analysis of the metastatic mass showed features of primary breast cancer of intracytoplasmic mucin and glandular formation in hematoxylin and eosin staining (Figure 2a). Immunohistochemical staining revealed apositive finding of mammaglobin (Figure 2b), gross cystic disease fluid protein 15 (Figure 2c) and P63 (Figure 2d).

The patient experienced no wound complications during follow-up after surgery. To date, she has been followed up on for three years after surgery and has shown no signs of malignancy (Figure 3).

\section{Discussion}

Breast cancer is one of the leading causes of death in women [7]. Despite advances in systemic adjuvant therapy that have led to increased survival rates of women with breast cancer [8], recurrent breast cancer is still frequently lethal [9]. Approximately 5 to $10 \%$ of patients who undergo mastectomy for operable breast cancer will develop a chest wall or regional nodal recurrence within 10 years after surgery [10]. There is wide variability in the reported incidence of simultaneous locoregional and distant metastases (10 to 60\%) [10-16]. However, approximately one-third of patients who present with a postmastectomy locoregional recurrence have synchronous distant disease [10].

Axillary recurrence is uncommon $[17,18]$, and its symptoms are often initially vague. The initial involvement of the brachial plexus may be misinterpreted as a radiation- or chemotherapy-induced brachial plexopathy [19]. Delayed diagnosis and treatment of axillary recurrence may lead to tumor progression, which can include extensive
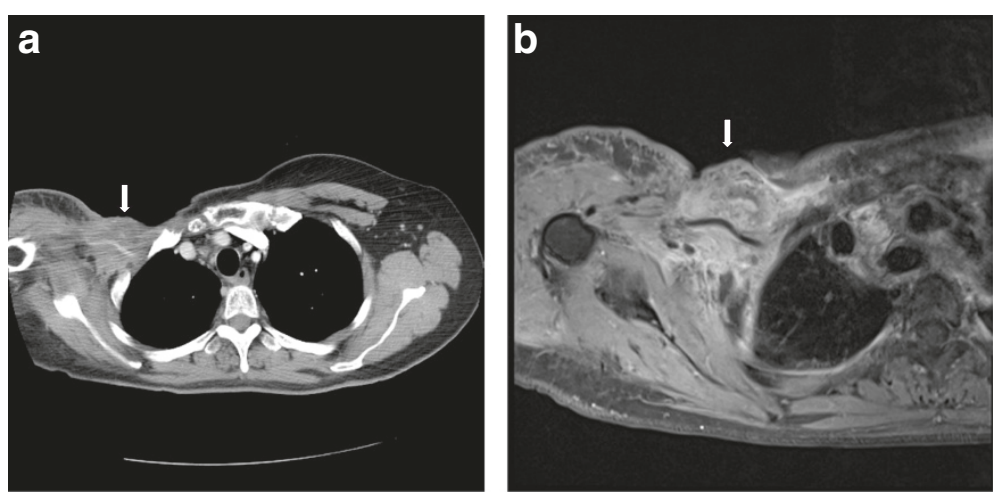

Figure 1 Preoperative coronal CT (a) and T1-weighted MRI (b) images of the tumor lesion surrounding the brachial plexus over the right axillary area with chest wall invasion (arrow). 

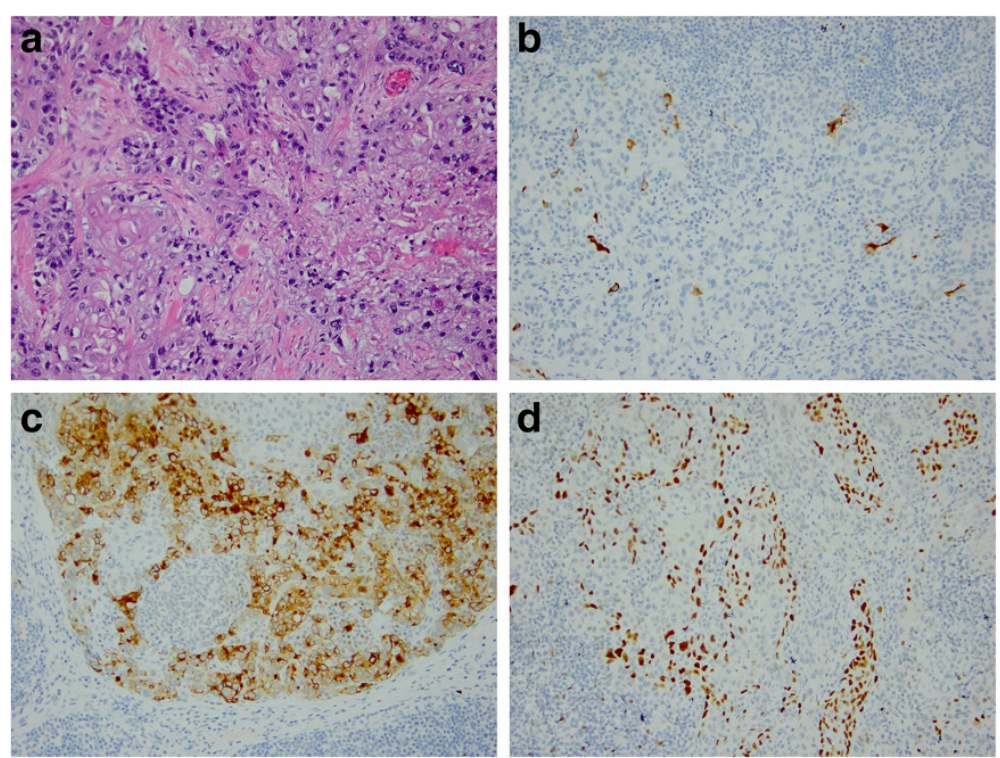

Figure 2 Micrographs of the samples came from the same block proved metastatic breast carcinoma. (a) Hematoxylin and eosin staining shows intracytoplasmic mucin and glandular formation. Immunohistochemical staining for (b) mammaglobin, (c) gross cystic disease fluid protein 15 and (d) P63. All images 200x magnification.

involvement of the brachial neurovascular bundle or underlying soft tissues [6,20]. Invasion of the brachial plexus and axillary vessels causes pain, limb dysfunction, lymphedema, paralysis and sensory impairment. Further, destruction of the overlying soft tissue leads to invasion of the chest wall, skin ulceration, hemorrhage and even bacterial or fungal infections and sepsis.

Decisions regarding therapy for local disease are often affected by whether the patient receives systemic treatment and the response to such therapy. For patients who may need a large resection, systemic therapy is preferable before resection not only to facilitate successful locoregional treatment, but also to eliminate any early metastases. Surgical treatment is useful for controlling pain and ulcers and maintaining the patient's quality of life [21]. However,

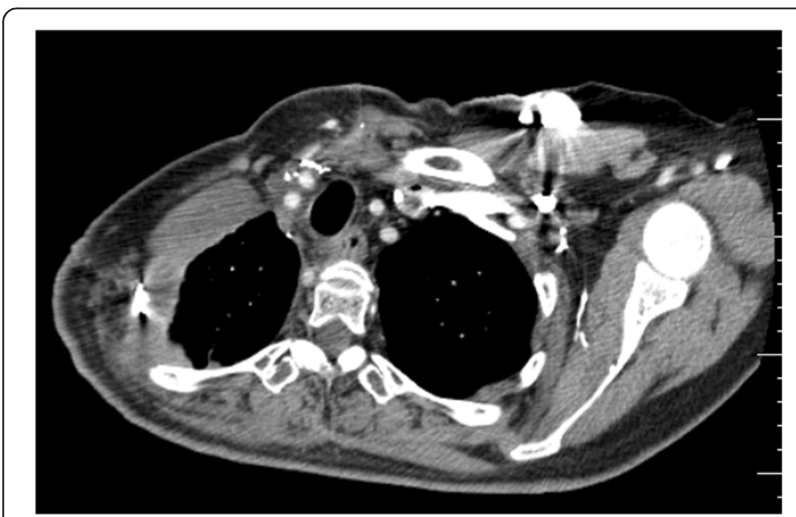

Figure $\mathbf{3}$ Coronal CT taken three years after surgery. There is no evidence of recurrence or invasion of malignancy. sometimes a more radical surgical intervention, such as amputation, is recommended in order to improve the patient's quality of life and ability to perform daily functions [20,22-24].

Although the majority of forequarter amputations are performed for high-grade bone and soft tissue sarcomas or extensive osteomyelitis of the upper extremities, this radical operation may also be recommendedfor the curative treatment of recurrent breast cancer or the palliation of locally advanced breast cancer [3-6,20,24-27]. The feasibility of completely reducing tumor burden through the use of wide excision depends on the degree of tumor invasion to neighboring vital organs. If the tumor involves the chest wall, an extended forequarter amputation could be performed, including resection of part of the chest wall $[6,28,29]$, sometimes in combination with a pneumonectomy [30-32]. In most patients, primary wound closure is achieved [33]. However, soft tissue reconstruction is requiredfor large defects that cannot achieve primary closure. For softtissue reconstruction various options have been used, such as split skin graft, pedicled omentoplasty [34], fasciocutaneous deltoid flap [33,35], free filet extremity flap [28] or in one case an osteomyocutaneous free flap that incorporated the elbow joint from the amputated extremity to reconstruct the shoulder contour [36].

Most patients who have needed forequarter amputation have had distant metastasis or other local-regional recurrence, and therefore the amputations were for palliative purposes. Thus, most patients survived less than two years after forequarter amputation [19,20,24-27]. However, in cases of solitary lesions that do not have associated 
Table 1 Reports of forequarter amputation for curative treatment of axillary recurrence breast cancer

\begin{tabular}{|c|c|c|c|c|c|c|c|}
\hline Reference & $\begin{array}{l}\text { Number of } \\
\text { patients }\end{array}$ & Age/Gender & Diagnosis & Indication & Wound complication & Local recurrence & Survival \\
\hline \multirow[t]{2}{*}{ Pressman [2] } & 2 & $55 / F$ & Recurrent & Curative & None delayed healing & None & A (48 months) \\
\hline & & $67 / F$ & & & & & A (36 months) \\
\hline Sakamura et al. [3] & 1 & $57 / F$ & Recurrent & Curative & Flap fringe necrosis & None & D (22 Months) \\
\hline Goodman et al. [5] & 1 & $56 / F$ & Recurrent & Curative & wound care flap necrosis & None & A (35 months) \\
\hline Ayvaz et al. [4] & 1 & $54 / \mathrm{M}$ & Recurrent & Curative & Not mentioned & $\begin{array}{l}\text { Lung metastasis at } \\
6 \text { months }\end{array}$ & D (11 months) \\
\hline Tsai et al. [current study] & 1 & $52 / F$ & Recurrent & Curative & None & None & A (36 months) \\
\hline
\end{tabular}

A: alive; D: dead.

comorbidities, forequarter amputation is recommended not only for relief of symptoms, but also for a chance of curative treatment. The literature (Table 1) documents five cases in which forequarter amputation was performed with the goal of a cure; three of these patients lived for at least three years after amputation. However, there was also a higher rate of wound complications $(60 \%$, three of five reported cases) when forequarter amputation was used with the goal of a cure because of the wider dissection margin and larger soft-tissue defect. The benefit of postoperative radiation is unclear, however, we do not recommend postoperative radiation in those who have been previously irradiated because of previous poor response and increased potential for wound and/or flap complications [37].

A multidisciplinary approach to breast cancer care is essential to the successful integration of available therapies [38-40]. When forequarter amputation is used for curative treatment, comprehensive treatment is needed throughout preoperative assessment, resection and the postoperative period. The forequarter amputation itself and skin graft, if needed, require a surgical team of orthopedic, general and plastic-reconstructive surgeons, while a team of radiologists, medical oncologists and radiation oncologists are needed for pre and postoperative evaluation and management. A comprehensive pain management team is also critical, not only to manage the patient's limb pain before surgery, as most patients who require forequarter amputation experience intractable and prolonged neurogenic pain prior to amputation [41,42], but also the phantom pain after radical amputations. Although significant pain relief is expected after a radial amputation, the literature indicates a $77 \%$ incidence of phantom limb pain after major limb amputation [41].

A rehabilitation team, including psychological support, is also essential. Psychological concerns for amputees include fear of the unknown, loss of self-esteem, loss of selfconfidence, fear of rejection and distress arising from having a malignant disease with a poor prognosis. This emotional distress can contribute to suicide [43], therefore, counseling is necessary before and after the surgery and psychological support is imperative for successful rehabilitation [44].

\section{Conclusions}

We have reported the rare clinical occurrence of localregional recurrence of breast cancer over an axillary area without distant metastases. For this patient, the tumor burden reached a point where salvage chemotherapy and radiation therapy were no longer useful due to the involvement of the brachial neurovascular bundle. Therefore, forequarter amputation was used. As this case indicates, in cases where limb-sparing surgical resection is not feasible, forequarter amputations not only play a role in relieving upper limb pain, but can provide a chance for a cure. Although this is a major amputation and can have significant associated morbidity, a dedicated multidisciplinary team can help to reduce complications and achieve a successful rehabilitation.

\section{Consent}

Written informed consent was obtained from the patient for publication of this case report and any accompanying images. A copy of the written consent is available for review by the Editor-in-Chief of this journal.

\section{Abbreviations}

CT: Computed tomography; MRI: Magnetic resonance imaging; PET: Positron emission tomography.

\section{Competing interests}

The authors declare that they have no competing interests.

\section{Authors' contributions}

CHT is first author and reviewed the medical record and drafted the manuscript. HET and WKJ reviewed the medical record and PGC reviewed the histology record. PF helped in medical record and manuscript preparation. YCF and $\mathrm{HCH}$ built up the study concepts. YY is the corresponding author. All authors read and approved the final manuscript.

\section{Acknowledgements}

The authors thank Keely Walker at City of Hope National Medical Center, Duarte, California for editing the manuscript.

\section{Author details}

${ }^{1}$ Department of Orthopedics, China Medical University Hospital, No. 91 Hsueh-Shih Road, Taichung 404, Taiwan. ${ }^{2}$ Graduate Institute of Clinical 
Medical Science, China Medical University, No. 91 Hsueh-Shih Road, Taichung 404, Taiwan. ${ }^{3}$ Division of Hematology/Oncology, Taichung Veterans General Hospital, 1650 Taiwan Boulevard Sect. 4, Taichung 40705, Taiwan. ${ }^{4}$ Taipei Medical University, 250 Wuxing Street, Taipei City 110, Taiwan. ${ }^{5}$ Department of Pathology, City of Hope National Medical Center, 1500 East Duarte Road, Duarte, CA 91010, USA. ${ }^{6}$ Department of Medical Oncology, City of Hope National Medical Center, 1500 East Duarte Road, Duarte, CA 91010, USA. ${ }^{7}$ School of Chinese Medicine, China Medical University, No. 91 Hsueh-Shih Road, Taichung 404, Taiwan. ${ }^{8}$ Department of Molecular Pharmacology, City of Hope National Medical Center and Beckman Research Center, 1500 East Duarte Road, Duarte, CA 91010, USA. ${ }^{9}$ The PhD Program for Cancer Biology and Drug Discovery, Taipei Medical University, 250 Wuxing Street, Taipei City 110, Taiwan.

Received: 13 February 2014 Accepted: 16 August 2014

Published: 18 November 2014

\section{References}

1. Pack G, Mcneer G, Coley B: Interscapulathoracic amputation for malignant tumors of the upper extremity: a report of 31 consecutive cases. Surg Gynecol Obstet 1942, 74:161-175.

2. Keevil JJ: Ralph Cuming and the interscapulothoracic amputation in 1808. J Bone Joint Surg (Br) 1949, 31B:589-595.

3. Pressman PI: Interscapulothoracic amputation for the complications of breast cancer: a new approach. Surgery 1974, 75:796-801.

4. Sakamura R, Nohira K, Shibata M, Sugihara T: Coverage of a large soft-tissue defect of the chest with a free fillet forearm and hand flap. $J$ Reconstr Microsurg 2001, 17:229-231.

5. Ayvaz M, Yilgor C, Mermerkaya MU, Konan A, Sonmez E, Acaroglu RE: Simultaneous forequarter amputation and radical mastectomy for metastatic breast carcinoma in a male patient: a case report. J Korean Surg Soc 2011, 81(Suppl 1):S6-S11.

6. Goodman MD, Mclntyre B, Shaughnessy EA, Lowy AM, Ahmad SA: Forequarter amputation for recurrent breast cancer: a case report and review of the literature. J Surg Oncol 2005, 92:134-141.

7. Jemal A, Bray F, Center MM, Ferlay J, Ward E, Forman D: Global cancer statistics. CA Cancer J Clin 2011, 61:69-90.

8. Berry DA, Cronin KA, Plevritis SK, Fryback DG, Clarke L, Zelen M, Mandelblatt JS, Yakovlev AY, Habbema JD, Feuer EJ: Effect of screening and adjuvant therapy on mortality from breast cancer. N Eng/ J Med 2005, 353:1784-1792.

9. Leonard RC, Rodger A, Dixon JM: ABC of breast diseases. Metastatic breast cancer. BMJ 1994, 309:1501-1504.

10. Buchanan CL, Dorn PL, Fey J, Giron G, Naik A, Mendez J, Murphy C, Sclafani LM: Locoregional recurrence after mastectomy: incidence and outcomes. J Am Coll surg 2006, 203:469-474.

11. Jacobson JA, Danforth DN, Cowan KH, d' Angelo T, Steinberg SM, Pierce L, Lippman ME, Lichter AS, Glatstein E, Okunieff P: Ten-year results of a comparison of conservation with mastectomy in the treatment of stage I and II breast cancer. N Engl J Med 1995, 332:907-911.

12. Schmoor C, Sauerbrei W, Bastert G, Schumacher M: Role of isolated locoregional recurrence of breast cancer: results of four prospective studies. J Clin Oncol 2000, 18:1696-1708.

13. Overgaard M, Hansen PS, Overgaard J, Rose C, Andersson M, Bach F, Kjaer M, Gadeberg CC, Mouridsen HT, Jensen MB, Zedeler K: Postoperative radiotherapy in high-risk premenopausal women with breast cancer who receive adjuvant chemotherapy. Danish Breast Cancer Cooperative Group 82b Trial. N Eng/ J Med 1997, 337:949-955.

14. Freedman GM, Fowble BL: Local recurrence after mastectomy or breast-conserving surgery and radiation. Oncology (Williston Park) 2000, 14:1561-1581.

15. Pisansky TM, Ingle JN, Schaid DJ, Hass AC, Krook JE, Donohue JH, Witzig TE, Wold LE: Patterns of tumor relapse following mastectomy and adjuvant systemic therapy in patients with axillary lymph node-positive breast cancer. Impact of clinical, histopathologic, and flow cytometric factors. Cancer 1993, 72:1247-1260.

16. Recht A, Gray R, Davidson NE, Fowble BL, Solin L, Cummings FJ, Falkson G, Falkson HC, Taylor SG, Tormey DC: Locoregional failure 10 years after mastectomy and adjuvant chemotherapy with or without tamoxifen without irradiation: experience of the Eastern Cooperative Oncology Group. J Clin Oncol 1999, 17:1689-1700.
17. Francissen CTP, Dings PM, Dalen T, Strobbe LA, Laarhoven HM, Wilt JW: Axillary recurrence after a tumor-positive sentinel lymph node biopsy without axillary treatment: a review of the literature. Ann Surg Oncol 2012, 19:4140-4149.

18. Hunt KK, Ballman KV, McCall LM, Boughey JC, Mittendorf EA, Cox CE, Whitworth PW, Beitsch PD, Leitch AM, Buchholz TA, Morrow MA, Giuliano AE: Factors associated with local-regional recurrence after a negative sentinel node dissection: results of the ACOSOG Z0010 trial. Ann Surg 2012, 256:428-436.

19. Behnke NK, Crosby SN, Stutz CM, Holt GE: Periscapular amputation as treatment for brachial plexopathy secondary to recurrent breast carcinoma: a case series and review of the literature. Eur J Surg Oncol 2013, 39:1325-1331.

20. Wittig JC, Bickels J, Kollender Y, Kellar-Graney KL, Meller I, Malawer MM: Palliative forequarter amputation for metastatic carcinoma to the shoulder girdle region: indications, preoperative evaluation, surgical technique, and results. J Surg Oncol 2001, 77:105-113. discussion 114

21. Jardines L, Callans LS, Torosian MH: Recurrent breast cancer: presentation, diagnosis, and treatment. Semin Oncol 1993, 20:538-547.

22. Merimsky O, Kollender Y, Inbar M, Lev-Chelouche D, Gutman M, Issakov J, Mazeh D, Shabat S, Bickels J, Meller I: Is forequarter amputation justified for palliation of intractable cancer symptoms? Oncology 2001, 60:55-59.

23. Malawer MM, Buch RG, Thompson WE, Sugarbaker PH: Major amputations done with palliative intent in the treatment of local bony complications associated with advanced cancer. J Surg Oncol 1991, 47:121-130.

24. Rickelt J, Hoekstra H, van Coevorden F, de Vreeze R, Verhoef C, van Geel AN: Forequarter amputation for malignancy. Br J Surg 2009, 96:792-798.

25. Holleb Al, Lucas JC Jr: Palliative interscapulothoracic amputation in the management of the breast cancer patient. Cancer 1959, 12:643-647.

26. Fanous N, Didolkar MS, Holyoke ED, Elias EG: Evaluation of forequarter amputation in malignant diseases. Surg Gynecol Obstet 1976, 142:381-384.

27. Mussey RD: Palliative forequarter amputation for recurrent breast carcinoma. AMA Arch Surg 1956, 73:154-156.

28. Wurlitzer FP: Improved technic for radical transthoracic forequarter amputation. Ann Surg 1973, 177:467-471.

29. Tran NV, Evans GR, Kroll SS, Miller MJ, Reece GP, Ainsle N, Robb GL: Free filet extremity flap: indications and options for reconstruction. Plast Reconstr Surg 2000, 105:99-104.

30. Fianchini A, Bertani A, Greco F, Brunelli A, Muti M: Transthoracic forequarter amputation and left pneumonectomy. Ann Thorac Surg 1996, 62:1841-1843.

31. Kuhn JA, Wagman LD, Lorant JA, Grannis FW, Dunst M, Dougherty WR, Jacobs DI: Radical forequarter amputation with hemithoracectomy and free extended forearm flap: technical and physiologic considerations. Ann Surg Oncol 1994, 1:353-359.

32. Geertzen JH, Hoekstra HJ, Elzinga A, Rietman JS: Rehabilitation management for a patient with a radical forequarter amputation with chest wall resection. Prosthet Orthot Int 1998, 22:254-257.

33. Ferrario T, Palmer $P$, Karakousis CP: Technique of forequarter (interscapulothoracic) amputation. Clin Orthop Relat Res 2004, 423:191-195.

34. Contant CME, van Geel AN, van der Holt B, Wiggers T: The pedicled omentoplasty and split skin graft (POSSG) for reconstruction of large chest wall defects. A validity study of 34 patients. Eur J Surg Oncol 1996, 22:532-537.

35. Volpe CM, Peterson S, Doerr RJ, Karakousis CP: Forequarter amputation with fasciocutaneous deltoid flap reconstruction for malignant tumors of the upper extremity. Ann Surg Oncol 1997, 4:298-302.

36. Osanai T, Kashiwa H, Ishikawa A, Takahara M, Ogino T: Improved shoulder contour following forequarter amputation with an osteomyocutaneous free flap from the amputated extremity: two cases. Br J Plast Surg 2005, 58:165-169.

37. Arbeit JM, Hilaris BS, Brennan MF: Wound complications in the multimodality treatment of extremity and superficial truncal sarcomas. J Clin Oncol 1987, 5:480-488.

38. Lyman GH, Baker J, Geradts J, Horton J, Kimmick G, Peppercorn J, Pruitt S, Scheri RP, Hwang ES: Multidisciplinary care of patients with early-stage breast cancer. Surg Oncol Clin N Am 2013, 22:299-317.

39. Shuster TD, Girshovich L, Whitney TM, Hughes KS: Multidisciplinary care for patients with breast cancer. Surg Clin North Am 2000, 80:505-533.

40. Saini KS, Taylor C, Ramirez A-J, Palmieri C, Gunnarsson U, Schmoll HJ, Dolci SM, Ghenne C, Metzger-Filho O, Skrzypski M, Paesmans M, Ameye L, Piccart-Gebhart MJ, de Azambuja E: Role of the multidisciplinary team in 
breast cancer management: results from a large international survey involving 39 countries. Ann Oncol 2012, 23:853-859.

41. Parsons CM, Pimiento JM, Cheong D, Marzban SS, Gonzalez RJ, Johnson D, Letson GD, Zager JS: The role of radical amputations for extremity tumors: a single institution experience and review of the literature. J Surg Oncol 2012, 105:149-155.

42. Nikolajsen L, Jensen TS: Phantom limb pain. Br J Anaesth 2001, 87:107-116.

43. Bhagia SM, Elek EM, Grimer RJ, Carter SR, Tillman RM: Forequarter amputation for high-grade malignant tumours of the shoulder girdle. J Bone Joint Surg (Br) 1997, 79:924-926.

44. Smurr LM, Gulick K, Yancosek K, Ganz O: Managing the upper extremity amputee: a protocol for success. J Hand Ther 2008, 21:160-175. quiz 176.

doi:10.1186/1477-7819-12-346

Cite this article as: Tsai et al:: Curative use of forequarter amputation for recurrent breast cancer over an axillary area: a case report and literature review. World Journal of Surgical Oncology 2014 12:346.

\section{Submit your next manuscript to BioMed Central and take full advantage of:}

- Convenient online submission

- Thorough peer review

- No space constraints or color figure charges

- Immediate publication on acceptance

- Inclusion in PubMed, CAS, Scopus and Google Scholar

- Research which is freely available for redistribution 